九州大学学術情報リポジトリ

Kyushu University Institutional Repository

\title{
INVERSE FUNCTIONAL EQUATIONS FOR BELLMAN'S ALLOCATION PROCESS
}

Iwamoto, Sei ichi

Department of Economic Engineering, Faculty of Economics, Kyushu University

https://doi.org/10.5109/13345

出版情報: Bulletin of informatics and cybernetics. 20 (3/4), pp.57-68, 1983-03. Research Association of Statistical Sciences

バージョン :

権利関係 : 


\title{
INVERSE FUNCTIONAL EQUATIONS FOR BELLMAN'S ALLOCATION PROCESS
}

\author{
By
}

\section{Seiichi Iw AmoTo*}

\begin{abstract}
This paper studies an inversion of functional equation for Bellman's infinite-stage allocation process. Obtaining a sufficient condition under which Bellman's (main) functional equation has a unique invertible solution, we propose additive- and recursive-inverse functional equations which have a common solution. It is proved that the additive-inverse functional equation has a unique solution in a moderate class of functions. The solution is obtained from two successive approximation methods.
\end{abstract}

\section{Introduction}

One of the most interesting features of dynamic programming is found in the functional equation

$$
\begin{aligned}
& f(x)=\operatorname{Max}_{0 \leq y \leq x}[g(y)+h(x-y)+f(a y+b(x-y))] \quad x \geqq 0 \\
& f(0)=0
\end{aligned}
$$

which was introduced by Bellman [1, Chap. 1]. The equation (1) seems to involve all the essences of dynamic programming. Bellman proved among many others that under some moderate assumptions the equation (1) has a unique solution which is continuous at 0 .

This paper continues Bellman's work [1, Chap. 1] with three purposes of developing his functional equation treatment to a kind of dual theory. The first purpose is to prove under the additional assumption "invertibility of $g, h$ " the existence of a unique "invertible" solution $f$ of (1). The existence in turn enables us to propose two inverse functional equations

$$
\begin{aligned}
& u(z)=\operatorname{Min}_{0 \leqq y \leqq x=f^{-1}(z)}[(1-b) x+(b-a) y+u(z-g(y)-h(x-y))] \quad z \geqq 0 \\
& u(0)=0
\end{aligned}
$$

and

$$
\begin{aligned}
& v(z)=\operatorname{Min}_{0 \leqq y \leqq x=f^{-1}(z)} \frac{1}{b}[(b-a) y+v(z-g(y)-h(x-y))] \quad z \geqq 0 \\
& v(0)=0
\end{aligned}
$$

* Department of Economic Engineering, Faculty of Economics, Kyushu University 27, Fukuoka 812, Japan. 
where $0 \leqq b<1$ for (5) and for $0<b<1$ for (6), respectively. The equation (5) does not admit the trivial solution. But, (6) admits. The former will turn out to be more attractive than the latter. If we formally weaken the condition $x=f^{-1}(z)$ to $x<\infty$ in (5), then the resulting equation becomes an infinite-version of the recursive formula

$$
\begin{aligned}
& u_{1}(z)=\operatorname{Min}_{g\left(y_{1}\right)+h\left(y_{2}\right)=z}\left[(1-a) y_{1}+(1-b) y_{2}\right] \\
& u_{n+1}(z)=\operatorname{Min}_{y_{1}, y_{2} \geq 0}\left[(1-a) y_{1}+(1-b) y_{2}+u_{n}\left(z-g\left(y_{1}\right)-h\left(y_{2}\right)\right)\right]
\end{aligned}
$$

for Bellman's finite-stage process [1, p. 45, No. 20]. However, both in problem setting and in its analysis, imposing the constraint $x=f^{-1}(z)$ will play a crucial role in this paper.

The second purpose is to show that both equations (5) and (6) have a common solution $f^{-1}$. The proof justifies the introduction of (5) and (6). The third purpose is to prove the uniqueness of the solution of (5) in the class of functions which are nonnegative and continuous at 0 .

The inverse theory of finite-stage dynamic programming which escapes the functional equation treatment has been extensively studied by the author [2-9].

\section{Bellman's Basic Functional Equation}

In this section we shall prepare Bellman's basic functional equation for an infinitestage allocation process [1, Chap. 1].

Under the following assumptions

a. $g, h:[0, \infty) \rightarrow[0, \infty)$ are continuous and $g(0)=h(0)=0$.

$\mathrm{a}^{\prime} . \quad g, h$ are strictly increasing and $g(\infty)=h(\infty)=\infty$.

b. If $m(x)=\operatorname{Max}_{0 \leqq y \leqq x} \operatorname{Max}(g(y), h(y))$ and $c=\operatorname{Max}(a, b)$, then $\sum_{n=0}^{\infty} m\left(c^{n} x\right)<\infty$ for all $x \geqq 0$.

c. $0 \leqq a<1,0 \leqq b<1$.

we consider the functional equation

$$
\begin{aligned}
& f(x)=\operatorname{Max}_{0 \leqq y \leqq x}[g(y)+h(x-y)+f(a y+b(x-y))] \quad x \geqq 0 \\
& f(0)=0 .
\end{aligned}
$$

This is called main functional equation. Let $f(x)$, if it exists, be the maximum value of $\sum_{n=0}^{\infty}\left[g\left(y_{n}\right)+h\left(x_{n}-y_{n}\right)\right]$ over the infinite-stage resource-allocation process $x_{n+1}=a y_{n}+$ $b\left(x_{n}-y_{n}\right), 0 \leqq y_{n} \leqq x_{n}, n \geqq 0$ with an initial resource $x_{0}=x$, then the maximum total reward function $f$ satisfies the main functional equation (1). However, every solution of (1) does not represent the maximum value of this allocation process. This fact leads us to the mathematical problem of existence and uniqueness. The following basic result is due to Bellman.

THEOREM 1 (Bellman [1, p. 12]) Under Assumptions $a, b$ and $c$, there exists a unique solution of (1) which is continuous at 0 . Moreover, this function is continuous on $[0, \infty)$.

The proof is based upon the successive approximation method. Let us define the sequence $\left\{f_{n}\right\}$ as follows. 


$$
\begin{aligned}
& f_{1}(x)=\operatorname{Max}_{0 \leqq y \leqq x}[g(y)+h(x-y)] \quad x \geqq 0 \\
& f_{n+1}(x)=\operatorname{Max}_{0 \leqq y \leqq x}\left[g(y)+h(x-y)+f_{n}(a y+b(x-y))\right] \quad x \geqq 0, n \geqq 1 .
\end{aligned}
$$

Then it converges to the unique solution of (1).

\section{Invertible Functional Equation}

Our first aim is to obtain an invertible solution of (1). Under the additional assumption $a^{\prime}$, this will be the case.

LEMmA 1. Under Assumptions $a, a^{\prime}, b$ and $c$, the sequence $\left\{f_{n}\right\}$ enjoys the following properties.

(i) $f_{n}:[0, \infty) \rightarrow[0, \infty)$ is continuous strictly increasing and $f_{n}(0)=0, f_{n}(\infty)=\infty$ for $n \geqq 1$.

(ii) $f_{n}(x) \leqq f_{n+1}(x)$ on $[0, \infty)$ for $n \geqq 1$. Moreover, if $a>0$ and $b>0$, then $f_{n}(x)<$ $f_{n+1}(x)$ on $(0, \infty)$.

(iii) $\left\{f_{n}\right\}$ converges uniformly on any finite interval of $[0, \infty)$. The convergence is monotone increasing.

(iv) The limit function $f:[0, \infty) \rightarrow[0, \infty)$ is continuous strictly increasing and $f(0)=0$, $f(\infty)=\infty$. Moreover, it is a solution of (1).

PROof. Bellman's proof is fundamental [1, p. 12-16]. It suffices to prove only the following additional results not claimed in his proof.

A. Strict increasingness of $f_{n}$.

Let $x_{1}<x_{2}$. Let $y_{1}(x)$ be a maximizer of (2). Then we have

$$
\begin{array}{rlrl}
f_{1}\left(x_{1}\right) & =g\left(y_{1}\left(x_{1}\right)\right)+h\left(x_{1}-y_{1}\left(x_{1}\right)\right) & \\
& <g\left(y_{1}\left(x_{1}\right)\right)+h\left(x_{2}-y_{1}\left(x_{1}\right)\right) & & (\text { strict increasingness of } h) \\
& \leqq \operatorname{Max}_{0 \leq y \leq x_{2}}[g(y)+h(x-y)] & & \left(0 \leqq y_{1}\left(x_{1}\right) \leqq x_{1}<x_{2}\right) \\
& =f_{1}\left(x_{2}\right) . &
\end{array}
$$

Further let $f_{n}$ be strictly increasing and $y_{n}(x)$ be a maximizer of (3). Then iwe have

$$
\begin{aligned}
f_{n+1}\left(x_{1}\right) & =g\left(y_{n}\left(x_{1}\right)\right)+h\left(x_{1}-y_{n}\left(x_{1}\right)\right)+f_{n}\left(a y_{n}\left(x_{1}\right)+b\left(x_{1}-y_{n}\left(x_{1}\right)\right)\right) \\
& <g\left(y_{n}\left(x_{1}\right)\right)+h\left(x_{2}-y_{n}\left(x_{1}\right)\right)+f_{n}\left(a y_{n}\left(x_{1}\right)+b\left(x_{2}-y_{n}\left(x_{1}\right)\right)\right) \\
& \left.\quad \text { (strict increasingness of } h \text { and } f_{n}\right) \\
& \leqq \operatorname{Max}_{0 \leqq y \leqq x_{2}}\left[g(y)+h\left(x_{2}-y\right)+f_{n}\left(a y+b\left(x_{2}-y\right)\right)\right] \\
& =f_{n+1}\left(x_{2}\right) .
\end{aligned}
$$

B. $f_{1}(\infty)=\infty$.

For any large $M>0$, there exists an $x>0$ such that $g(x / 2) \geqq M$ and $h(x / 2) \geqq M$. Hence, for any $y$ in $[0, x]$, it holds that either $g(y) \geqq M$ or $h(x-y) \geqq M$. Thus we obtain

$$
\begin{aligned}
f_{1}(x) & =\operatorname{Max}_{0 \leqq y \leq x}[g(y)+h(x-y)] \\
& \geqq M .
\end{aligned}
$$


(Similarly, $f_{n}(\infty)=\infty$ is inductively proved).

C. $f_{n}(x)<f_{n+1}(x)$.

Let $0<a, b<1$. Then for $x>0$ we have

$$
\begin{aligned}
f_{1}(x) & =g\left(y_{1}(x)\right)+h\left(x-y_{1}(x)\right) \\
& <g\left(y_{1}(x)\right)+h\left(x-y_{1}(x)\right)+f_{1}\left(a y_{1}(x)+b\left(x-y_{1}(x)\right)\right) \\
& \quad\left(f_{1}(x)>0 \text { for } x>0\right) \\
& \leqq \operatorname{Max}_{0 \leqq y \leqq x}\left[g(y)+h(x-y)+f_{1}(a y+b(x-y))\right] \\
& =f_{2}(x) .
\end{aligned}
$$

Assuming that $f_{n-1}(x)<f_{n}(x)$ on $(0, \infty)$, we further obtain

$$
\begin{aligned}
f_{n}(x) & =g\left(y_{n-1}(x)\right)+h\left(x-y_{n-1}(x)\right)+f_{n-1}\left(a y_{n-1}(x)+b\left(x-y_{n-1}(x)\right)\right) \\
& <g\left(y_{n-1}(x)\right)+h\left(x-y_{n-1}(x)\right)+f_{n}\left(a y_{n-1}(x)+b\left(x-y_{n-1}(x)\right)\right) \\
& \leqq \operatorname{Max}_{0 \leq y \leq x}\left[g(y)+h(x-y)+f_{n}(a y+b(x-y))\right] \quad\left(f_{n}(x)>0 \text { for } x>0\right) \\
& =f_{n+1}(x) .
\end{aligned}
$$

D. $f_{n}(\infty)=\infty$ for $n \geqq 2$ and $f(\infty)=\infty$.

This (strict) monotonicity together with $f_{1}(\infty)=\infty$ implies $f_{n}(\infty)=\infty$ for $n \geqq 2$ and $f(\infty)=\infty$.

E. $f(0)=0$.

This is a direct consequence of $f_{n}(0)=0$ for $n \geqq 1$.

F. Strict increasingness of $f$.

Let $0 \leqq x_{1}<x_{2}$ and $y(x)$ be a maximizer of (1). Then we have

$$
\begin{aligned}
f\left(x_{1}\right) & =g\left(y\left(x_{1}\right)\right)+h\left(x_{1}-y\left(x_{1}\right)\right)+f\left(a y\left(x_{1}\right)+b\left(x_{1}-y\left(x_{1}\right)\right)\right) \\
& <g\left(y\left(x_{1}\right)\right)+h\left(x_{2}-y\left(x_{1}\right)\right)+f\left(a y\left(x_{1}\right)+b\left(x_{2}-y\left(x_{1}\right)\right)\right) \\
& \leqq \operatorname{Max}_{0 \leqq y x_{2}}\left[g(y)+h\left(x_{2}-y\right)+f\left(a y+b\left(x_{2}-y\right)\right)\right] \\
& =f\left(x_{2}\right) . \\
& \left(0 \leqq y\left(x_{1}\right) \leqq x_{1}<x_{2}\right)
\end{aligned}
$$

This completes the proof of Lemma 1.

Thus, Lemma 1 leads us to show

THEOREM 2. Under Assumptions $a, a^{\prime}, b$ and $c$, there exists a unique solution of (1) which is continuous at 0 . Moreover, this function is strictly increasing continuous and goes to infinity as so does $x$.

\section{Two Inverse Functional Equations}

Throughout the remainder of the paper we always assume $a, a^{\prime}, b$ and $c$. Then Theorem 2 shows us that the unique solution $f$ of (1) which is continuous at 0 is invertible. The inverse function $f^{-1}$ satisfies $f^{-1}(0)=0, f^{-1}(\infty)=\infty$ and strict increasingness like as $g, h$ and $f$.

The next lemma will take an important part in the remainder of the paper. 
Lemma 2. The condition $0 \leqq y \leqq x=f^{-1}(z)$ implies

$$
\begin{aligned}
z-g(y)-h(x-y) & \geqq f(a y+b(x-y)) \\
& \geqq f\left(d f^{-1}(z)\right) \\
& \geqq 0
\end{aligned}
$$

where $d=\operatorname{Min}(a, b)$.

PROOF. Let $0 \leqq y \leqq x=f^{-1}(z)$. Then we have

$$
\begin{aligned}
z & =f(x) \\
& =\operatorname{Max}_{0 \leqq y^{\prime} \leqq x}\left[g\left(y^{\prime}\right)+h\left(x-y^{\prime}\right)+f\left(a y^{\prime}+b\left(x-y^{\prime}\right)\right)\right] \\
& \geqq g(y)+h(x-y)+f(a y+b(x-y)) .
\end{aligned}
$$

Since $f(x) \geqq 0$ for $x \geqq 0$, this leads to

$$
\begin{aligned}
z-g(y)-h(x-y) & \geqq f(a y+b(x-y)) \\
& \geqq f(d x) \\
& =f\left(d f^{-1}(z)\right) \\
& \geqq 0,
\end{aligned}
$$

which completes the proof.

Lemma 2 enables us to consider the functional equation

$$
\begin{aligned}
& u(z)=\operatorname{Min}_{0 \leq y \leq x=f^{-1}(z)}[(1-b) x+(b-a) y+u(z-g(y)-h(x-y))] \quad z \geqq 0 \\
& u(0)=0
\end{aligned}
$$

rather than the equation

$$
\begin{aligned}
& u(z)=\operatorname{Min}_{\substack{0 \leqq y \leqq x=f^{-1}(z) \\
0 \leqq g(y)+h(x-y) \leqq z}}[(1-b) x+(b-a) y+u(z-g(y)-h(x-y))] \quad z \geqq 0 \\
& u(0)=0 .
\end{aligned}
$$

That is, the constraint $0 \leqq g(y)+h(x-y) \leqq z$ is redundant for treating functional equations involving optimization under the condition $0 \leqq y \leqq x=f^{-1}(z)$. We call (5) additive-inverse functional equation of (1). We always keep our mind on the equality

$$
\begin{aligned}
(1-b) x+(b-a) y & =(1-a) y+(1-b)(x-y) \\
& =x-(a x+b(x-y)) .
\end{aligned}
$$

It is considered that $u(z)$, if it exists, represents the minimum value of

$$
\sum_{n=0}^{\infty}\left[(1-b) x_{n}+(b-a) y_{n}\right]
$$

over the infinite-stage total-reward-decrease process $z_{n+1}=z_{n}-g\left(y_{n}\right)-h\left(x_{n}-y_{n}\right), 0 \leqq y_{n}$ $\leqq x_{n}=f^{-1}\left(z_{n}\right), n \geqq 0$ with a preassigned total reward $z_{0}=z$. We see that any total cost is roughly evaluated as follows.

$$
\begin{aligned}
\sum_{n=0}^{\infty}\left[(1-b) x_{n}+(b-a) y_{n}\right] & \geqq(1-c) \sum_{n=0}^{\infty} x_{n} \\
& \geqq(1-c) f^{-1}(z) .
\end{aligned}
$$


Thus, the minimum value is larger than or equal to $(1-c) f^{-1}(z)$. This lower bound makes the additive-inverse functional equation more attractive. This equation does not admit the trivial solution.

On the other hand, another inverse functional equation is introduced as follows. For $0<b<1$ we consider

$$
\begin{aligned}
& v(z)=\operatorname{Min}_{0 \leqq y \leqq x=f^{-1}(z)} \frac{1}{b}[(b-a) y+v(z-g(y)-h(x-y))] \quad z \geqq 0 \\
& v(0)=0 .
\end{aligned}
$$

This is called recursive-inverse functional equation of (1). It is considered that $v(z)$, if it exists, represents the minimum value of $\sum_{n=0}^{\infty} \frac{(b-a)}{b^{n+1}} y_{n}$ over the total-reward-decrease process stated above. Any path with $y_{n} \equiv 0$ yields zero value. Thus, the minimum value attains zero for $b \geqq a$. The recursive-inverse functional equation admits the trivial solution for $b \geqq a$. This triviality escapes a further discussion of the equation (6).

For $N$-stage main dynamic program (DP), the recursive-inverse DP is introduced in $[2-5,7]$ and the additive-inverse DP in [8]. For infinite-stage DP, the recursive inversion is applied in [6]. The author [9] has investigated the additive inversion of continuous-time DP.

The derivation of equations (5) and (6) will be justified in the proof of Theorem 3.

\section{Common Solution}

THEOREM 3. Both equations (5) and (6) have a common solution $f^{-1}$.

Proof. Let $f$ be the unique solution of (1) which is continuous at 0 . Then for any $z \geqq 0$ there exists a unique $x \geqq 0$ with

$$
z=f(x)=\operatorname{Max}_{0 \leq y \leq x}[g(y)+h(x-y)+f(a y+b(x-y))] .
$$

From (7) we have

$$
z \geqq g(y)+h(x-y)+f(a y+b(x-y)) \quad \text { for } \quad 0 \leqq y \leqq x=f^{-1}(z)
$$

which is equivalent to

$$
f^{-1}(z-g(y)-h(x-y)) \geqq a y+b(x-y) \quad \text { for } \quad 0 \leqq y \leqq x=f^{-1}(z) .
$$

That is, (7) implies

$$
(b-a) y+f^{-1}(z-g(y)-h(x-y)) \geqq b x \quad \text { for } \quad 0 \leqq y \leqq x=f^{-1}(z) .
$$

First, adding $(1-b) x$ to both-hand sides of $(10)$, we obtain

$$
(1-b) x+(b-a) y+f^{-1}(z-g(y)-h(x-y)) \geqq x \quad \text { for } \quad 0 \leqq y \leqq x=f^{-1}(z) .
$$

This leads to

$$
\operatorname{Inf}_{0 \leq y \leq x=f^{-1}(z)}\left[(1-b) x+(b-a) y+f^{-1}(z-g(y)-h(x-y))\right] \geqq f^{-1}(z) .
$$

Second, dividing both-hand sides of $(10)$ by $b(0<b<1)$, we have

$$
\frac{1}{b}\left[(b-a) y+f^{-1}(z-g(y)-h(x-y))\right] \geqq x \quad \text { for } \quad 0 \leqq y \leqq x=f^{-1}(z) .
$$


This in turn yields

$$
\operatorname{Inf}_{0 \leqq y \leqq x=f^{-1}(z)} \frac{1}{b}\left[(b-a) y+f^{-1}(z-g(y)-h(x-y))\right] \geqq f^{-1}(z) .
$$

Furthermore, (7) together with its maximizer $y(x)$ implies

$$
z=g(y(x))+h(x-y(x))+f(a y(x)+b(x-y(x))) \quad \text { for } \quad x=f^{-1}(z) .
$$

Accordingly we see that (13) yields both

$$
(1-b) x+(b-a) y(x)+f^{-1}(z-g(y(x))-h(x-y(x)))=f^{-1}(z)
$$

and

$$
\frac{1}{b}\left[(b-a) y(x)+f^{-1}(z-g(y(x))-h(x-y(x)))\right]=f^{-1}(z)
$$

where $x=f^{-1}(z)$. From (11), $\left(11^{\prime}\right),(12)$ and $\left(12^{\prime}\right)$, we have a common solution $f^{-1}$ of (5) and (6). This completes the proof.

\section{Maximality and Minimality}

Our second aim is to obtain a uniqueness theorem. This will be done after discussion on maximal and minimal solutions. Each solution will be obtained through the usual approach for uniqueness of solution to dynamic programming functional equation $[1$, p. 15,16$]$.

THEOREM 4. The $f^{-1}$ is the largest solution of (5) which is continuous at 0 .

Proof. Let $v$ be any solution of (5) which is continuous at 0 . Then we have for a minimizer $y(x)$ of $(5)$

$$
\begin{aligned}
v(z) & =\operatorname{Min}_{0 \leqq y \leqq x=f^{-1}(z)}[(1-b) x+(b-a) y+v(z-g(y)-h(x-y))] \\
& \leqq(1-b) x+(b-a) y(x)+v(z-g(y(x))-h(x-y(x)))
\end{aligned}
$$

and

$$
f^{-1}(z)=(1-b) x+(b-a) y(x)+f^{-1}(z-g(y(x))-h(x-y(x)))
$$

where $x=f^{-1}(z)$. From (14), (15) we have

$$
v(z)-f^{-1}(z) \leqq v(z-g(y(x))-h(x-y(x)))-f^{-1}(z-g(y(x))-h(x-y(x)))
$$

and

$$
\begin{aligned}
z-g(y(x))-h(x-y(x)) & =f(x-(1-b) x-(b-a) y(x)) \\
& =f(a y(x)+b(x-y(x))) \\
& \leqq f(c x) \\
& =f\left(c f^{-1}(z)\right) .
\end{aligned}
$$

Let us now define

$$
U(w)=\operatorname{Sup}_{0 \leqq z \leqq w}\left(v(z)-f^{-1}(z)\right) .
$$

Then $U$ is continuous at 0 and has the value 0 there. From (16), (17) and (18) we obtain

$$
U(w) \leqq U\left(f\left(c f^{-1}(w)\right)\right)
$$


whence, by iteration,

$$
U(w) \leqq U\left(f\left(c^{n} f^{-1}(w)\right)\right) \quad \text { for } \quad n \geqq 1 .
$$

Here we remark that $f\left(c^{n} f^{-1}(w)\right)$ decreases monotonically to 0 as $n$ goes to $\infty$. Since $U$ is continuous at 0 and $U(0)=0$, upon letting $n \rightarrow \infty$, we obtain $U(w) \leqq 0$, and thus that $v(z) \leqq f^{-1}(z)$. This completes the proof of maximality.

This maximality theorem in turn yields a minimality of $f^{-1}$ for $0 \leqq a, b<1 / 2$.

THEOREM 5. If $0 \leqq a, b<1 / 2$, then $f^{-1}$ is the smallest solution of (5) which is continuous strictly increasing and goes to infinity as so does $z$.

Proof. Let $v$ be any solution of (5) which is continuous strictly increasing and $v(\infty)=\infty$, and $\hat{y}(x)$ be a corresponding minimizer. Then we have

$$
v(z)=(1-b) x+(b-a) \hat{y}(x)+v(z-g(\hat{y}(x))-h(x-\hat{y}(x)))
$$

and

$$
\begin{aligned}
f^{-1}(z) & =\operatorname{Min}_{0 \leqq y \leq x=f^{-1}(z)}\left[(1-b) x+(b-a) y+f^{-1}(z-g(y)-h(x-y))\right] \\
& \leqq(1-b) x+(b-a) \hat{y}(x)+f^{-1}(z-g(\hat{y}(x))-h(x-\hat{y}(x)))
\end{aligned}
$$

where $x=f^{-1}(z)$. From (21), (22) we in turn get

and

$$
\begin{aligned}
& f^{-1}(z)-v(z) \leqq f^{-1}(z-g(\hat{y}(x))-h(x-\hat{y}(x)))-v(z-g(\hat{y}(x))-h(x-y(x))), \\
& v(z) \geqq(1-b) x+(b-a) \hat{y}(x) \\
&=x-a \hat{y}(x)-b(x-\hat{y}(x)) \\
& \geqq x-c x \\
&=(1-c) f^{-1}(z)
\end{aligned}
$$

$$
\begin{aligned}
z-g(\hat{y}(x))-h(x-\hat{y}(x)) & =v^{-1}(v(z)-(1-b) x-(b-a) \hat{y}(x)) \\
& =v^{-1}(v(z)-x+a \hat{y}(x)+b(x-\hat{y}(x))) .
\end{aligned}
$$

Here we remark that Theorem 4 shows

$$
v(z)-x=v(z)-f^{-1}(z) \leqq 0 .
$$

From (25), (26) we have

$$
\begin{aligned}
z-g(\hat{y}(x))-h(x-\hat{y}(x)) & \leqq v^{-1}(a \hat{y}(x)+b(x-\hat{y}(x)) \\
& \leqq v^{-1}(c x) \\
& =v^{-1}\left(c f^{-1}(z)\right) .
\end{aligned}
$$

On the other hand, (24) leads to

$$
v^{-1}(u) \leqq f\left(\frac{u}{1-c}\right) .
$$

Combining (27) and (28), we have

$$
z-g(\hat{y}(x))-h(x-\hat{y}(x)) \leqq f\left(\frac{c}{1-c} f^{-1}(z)\right) .
$$

Let us now define

$$
L(w)=\operatorname{Max}_{0 \leqq z \leqq w}\left(f^{-1}(z)-v(z)\right) .
$$


Then $L$ is continuous and has the value 0 at $w=0$.

From (23), (29), (30) we obtain

$$
L(w) \leqq L\left(f\left(\frac{c}{1-c} f^{-1}(w)\right)\right),
$$

whence, by iteration,

$$
L(w) \leqq L\left(f\left(\left(\frac{c}{1-c}\right)^{n} f^{-1}(w)\right)\right) \quad n \geqq 1 .
$$

Here we remark that $0 \leqq c=\operatorname{Max}(a, b)<1 / 2$. Since $L$ is continuous and $L(0)=0$, upon letting $n \rightarrow \infty$, we obtain $L(w) \leqq 0$, and that $f^{-1}(z) \leqq v(z)$. This completes the proof of minimality.

COROLlARY 1. If $0 \leqq a, b<1 / 2$, then $f^{-1}$ is the unique solution of (5) which is continuous strictly increasing and goes to infinity as so does $z$.

COROLlary 2. Any solution $v$ of (5) which is nonnegative and continuous at 0 satisfies

$$
(1-c) f^{-1}(z) \leqq v(z) \leqq f^{-1}(z)
$$

\section{Uniqueness}

Corollary 2 gives us both upper and lower bounds. Theorem 4 shows us that the upper bound is most desirable. However, the lower bound is more improvable. This improvement is based upon the following lemma, which leads directly to uniqueness of the solution $f^{-1}$.

LEMMA 3. Any solution $v$ of (5) which is nonnegative and continuous at 0 satisfies

(i) $\frac{1-c}{1-d} f^{-1}(z) \leqq v(z) \leqq f^{-1}(z)$. If $a=b$, then $v=f^{-1}$.

(ii) $\left(1-c^{n}\right) f^{-1}(z) \leqq v(z) \leqq f^{-1}(z)$ for all $n \geqq 1$. Hence $v=f^{-1}$.

PROOF. Theorem 4 shows that $v \leqq f^{-1}$. It suffices to prove the lower boundedness.

(i) First, from Corollary 2 and Lemma 2, we have

$$
\begin{aligned}
v(z) & =\operatorname{Min}_{0 \leqq y \leqq x=f^{-1}(z)}[(1-a) y+(1-b)(x-y)+v(z-g(y)-h(x-y))] \\
& \geqq \operatorname{Min}_{0 \leqq y \leqq x=f^{-1}(z)}\left[(1-c) y+(1-c)(x-y)+(1-c) f^{-1}(z-g(y)-h(x-y))\right] \\
& \geqq(1-c) \operatorname{Min}_{0 \leqq y \leqq x=f^{-1}(z)}\left[x+f^{-1}(f(a y+b(x-y))]\right. \\
& =(1-c) \operatorname{Min}_{0 \leqq y \leqq x=f^{-1}(z)}[x+a y+b(x-y)] \\
& \geqq(1-c) \operatorname{Min}_{0 \leqq y \leqq x=f^{-1}(z)}[x+d x] \\
& =(1-c)(1+d) f^{-1}(z) .
\end{aligned}
$$

Second, this inequality in turn yields

$$
\begin{aligned}
v(z) & =\operatorname{Min}_{0 \leq y \leq x=f^{-1}(z)}[(1-a) y+(1-b)(x-y)+v(z-g(y)-h(x-y))] \\
& \geqq \operatorname{Min}_{0 \leqq y \leq x=f^{-1}(z)}\left[(1-c) y+(1-c)(x-y)+(1-c)(1+d) f^{-1}(z-g(y)-h(x-y))\right] \\
& \geqq(1-c)\left(1+d+d^{2}\right) f^{-1}(z) .
\end{aligned}
$$


We have successively

$$
v(z) \geqq(1-c)\left(\sum_{i=0}^{n} d^{i}\right) f^{-1}(z) \quad n \geqq 1 .
$$

Hence, by letting $n \rightarrow \infty$, we obtain

$$
v(z) \geqq \frac{1-c}{1-d} f^{-1}(z) .
$$

(ii) First, from Corollary 2 and Lemma 2, we have

$$
\begin{aligned}
v(z) & =\operatorname{Min}_{0 \leqq y \leqq x=f^{-1}(z)}[(1-a) y+(1-b)(x-y)+v(z-g(y)-h(x-y))] \\
& \geqq \operatorname{Min}_{0 \leqq y \leqq x=f^{-1}(z)}\left[x-(a y+b(x-y))+(1-c) f^{-1}(f(a y+b(x-y)))\right] \\
& =\operatorname{Min}_{0 \leqq y \leqq x=f^{-1}(z)}[x-c(a y+b(x-y))] \\
& \geqq \operatorname{Min}_{0 \leqq y \leqq x=f^{-1}(z)}[x-c(c x)] \\
& =\left(1-c^{2}\right) f^{-1}(z) .
\end{aligned}
$$

Second, this inequality in turn yields

$$
\begin{aligned}
v(z) & \geqq \operatorname{Min}_{0 \leqq y \leqq x=f^{-1}(z)}\left[x-(a y+b(x-y))+\left(1-c^{2}\right) f^{-1}(z-g(y)-h(x-y))\right] \\
& \geqq \operatorname{Min}_{0 \leqq y \leqq x=f^{-1}(z)}\left[x-(a y+b(x-y))+\left(1-c^{2}\right)(a y+b(x-y))\right] \\
& \geqq\left(1-c^{3}\right) f^{-1}(z) .
\end{aligned}
$$

Further, by iteration, we get

$$
v(z) \geqq\left(1-c^{n}\right) f^{-1}(z) \quad n \geqq 1 .
$$

Hence, upon letting $n \rightarrow \infty$, we obtain

This completes the proof.

$$
v(z) \geqq f^{-1}(z) .
$$

The following theorem covers both Corollary 1 in this paper and Theorem 10 in [8].

THEOREM 6. The functional equation (5) has the unique solution $f^{-1}$ which is nonnegative and continuous at 0.

Proof. This is a direct consequence of Lemma 3(ii).

\section{Two Successive Approximations}

The third aim is to prove that two successive approximations yield the solution $f^{-1}$ of (5). One approximation whose $n$-th feasible action space is time-invariant may be monotone increasing. The other approximation which is restricted to time-variant region is always monotone decreasing.

LEMma 4. Any sequence $\left\{v_{n}\right\}$ generated by

$$
v_{n+1}(z)=\operatorname{Min}_{0 \leq y \leq x=f^{-1}(z)}\left[(1-b) x+(b-a) y+v_{n}(z-g(y)-h(x-y))\right] \quad z \geqq 0, n \geqq 0
$$

where

$$
v_{0} \text { is continuous and } 0 \leqq v_{0}(z) \leqq f^{-1}(z)
$$


satisfies

(i) $v_{n}$ is continuous.

(ii) $\left(1-c^{n}\right) f^{-1}(z) \leqq v_{n}(z) \leqq f^{-1}(z)$ i.e., $-c^{n} f^{-1}(z) \leqq v_{n}(z)-f^{-1}(z) \leqq 0$. Thus, $\left\{v_{n}\right\}$ converges to $f^{-1}$.

(iii) If $v_{0}=0$, then the convergence is monotone increasing.

Proof. (i) The continuity is trivial. (ii) Let $y_{n}(x)$ be a minimizer of (32). Then we have

$$
v_{n+1}(z)=(1-a) y_{n}(x)+(1-b)\left(x-y_{n}(x)\right)+v_{n}\left(z-g\left(y_{n}(x)\right)-h\left(x-y_{n}(x)\right)\right)
$$

where $x=f^{-1}(z)$. Since $v_{0} \geqq 0$, this leads to

$$
\begin{aligned}
v_{1}(z) & \geqq(1-a) y_{1}(x)+(1-b)\left(x-y_{1}(x)\right) \\
& \geqq(1-c) y_{1}(x)+(1-c)\left(x-y_{1}(x)\right) \\
& =(1-c) f^{-1}(z) .
\end{aligned}
$$

On the other hand, $v_{0} \leqq f^{-1}$ implies

$$
\begin{aligned}
v_{1}(z) & =\operatorname{Min}_{0 \leqq y \leqq x=f^{-1}(z)}\left[(1-b) x+(b-a) y+v_{\mathrm{v}}(z-g(y)-h(x-y))\right] \\
& \leqq \operatorname{Min}_{0 \leqq y \leqq x=f^{-1}(z)}\left[(1-b) x+(b-a) y+f^{-1}(z-g(y)-h(x-y))\right] \\
& =f^{-1}(z) .
\end{aligned}
$$

Further assuming that $\left(1-c^{n}\right) f^{-1} \leqq v_{n} \leqq f^{-1}$, we have

and

$$
\begin{aligned}
v_{n+1}(z) & \geqq x-\left(a y_{n}(x)+b\left(x-y_{n}(x)\right)\right)+\left(1-c^{n}\right) f^{-1}\left(z-g\left(y_{n}(x)\right)-h\left(x-y_{n}(x)\right)\right) \\
& \geqq x-\left(a y_{n}(x)+b\left(x-y_{n}(x)\right)\right)+\left(1-c^{n}\right)\left(a y_{n}(x)+b\left(x-y_{n}(x)\right)\right) \\
& \geqq\left(1-c^{n+1}\right) f^{-1}(z)
\end{aligned}
$$

$$
\begin{aligned}
v_{n+1}(z) & \leqq \operatorname{Min}_{0 \leqq y \leq x=f^{-1}(z)}\left[(1-b) x+(b-a) y+f^{-1}(z-g(y)-h(x-y))\right] \\
& =f^{-1}(z) .
\end{aligned}
$$

(iii) Let $v_{0}=0$. Then (35) leads to $v_{1}(z) \geqq v_{0}(z)=0$. Assuming that $v_{n} \geqq v_{n-1}$, we have

$$
\begin{aligned}
v_{n+1}(z) & =\operatorname{Min}_{0 \leqq y \leqq x=f^{-1}(z)}\left[(1-b) x+(b-a) y+v_{n}(z-g(y)-h(x-y))\right] \\
& \geq \operatorname{Min}_{0 \leqq y \leqq x=f^{-1}(z)}\left[(1-b) x+(b-a) y+v_{n-1}(z-g(y)-h(x-y))\right] \\
& =v_{n}(z) .
\end{aligned}
$$

This completes the proof.

Lemma 4 gives us the proof of Theorem 7 .

THEOREM 7. Any sequence $\left\{v_{n}\right\}$ generated by (32), (33) converges to the solution $f^{-1}$ of (5). If $v_{0}=0$, then the convergence is monotone increasing.

Another approximation is finite-stage approximation for the infinite-stage inverse process as follows.

THEOREM 8. Let $\left\{f_{n}\right\}$ be defined in (2), (3). Let $\left\{u_{n}\right\}$ be defined as follows.

$$
u_{1}(z)=f_{1}^{-1}(z)
$$




$$
\begin{array}{r}
u_{n+1}(z)=\operatorname{Min}_{0 \leqq y \leqq x=f_{n+1}^{-1}(z)}\left[(1-a) y+(1-b)(x-y)+u_{n}(z-g(y)-h(x-y))\right] \\
z \geqq 0, n \geqq 1 .
\end{array}
$$

Then we have

(i) $u_{n}=f_{n}^{-1} \quad n \geqq 1$.

(ii) $\left\{u_{n}\right\}$ converges monotone-decreasingly to the solution $f^{-1}$ of (5).

Proof. (i) Assume that $u_{1}=f_{1}^{-1}$. Let $0 \leqq y \leqq x=f_{2}^{-1}(z)$. Then we have

$$
\begin{aligned}
z=f_{2}(x) & =\operatorname{Max}_{0 \leqq y^{\prime} \leqq x}\left[g\left(y^{\prime}\right)+h\left(x-y^{\prime}\right)+f_{1}\left(a y^{\prime}+b\left(x-y^{\prime}\right)\right)\right] \\
& \geqq g(y)+h(x-y)+f_{1}(a y+b(x-y)) .
\end{aligned}
$$

From $u_{1}=f_{1}^{-1}$, we obtain

$$
(1-a) y+(1-b)(x-y)+u_{1}(z-g(y)-h(x-y)) \geqq x
$$

for all $y$ with $0 \leqq y \leqq x=f_{2}^{-1}(z)$. Further it follows that for a maximizer $y_{2}(x)$ of (3) for $n=1$

$$
(1-a) y_{2}(x)+(1-b)\left(x-y_{2}(x)\right)+u_{1}\left(z-g\left(y_{2}(x)\right)-h\left(x-y_{2}(x)\right)\right)=x .
$$

From (38), (39) we obtain

$$
f_{2}^{-1}(z)=\operatorname{Min}_{0 \leq y \leq x=f_{2}^{-1}(z)}\left[(1-a) y+(1-b)(x-y)+u_{1}(z-g(y)-h(x-y))\right],
$$

which implies $u_{2}=f_{2}^{-1}$. Moreover, $u_{n}=f_{n}^{-1}$ is inductively proved.

(ii) Since $\left\{f_{n}\right\}$ converges monotone-increasingly to $f$ (Lemma 1 ), the inverse function $f_{n}^{-1}=u_{n}$ converges monotone-decreasingly to $f^{-1}$. On the other hand, $f^{-1}$ is a solution of (5) (Theorem 3). This completes the proof.

\section{References}

[1] Bellman, R.: Dynamic Programming, Princeton University Press, Princeton, N. J., 1957.

[2] Iwamoto, S.: Inverse dynamic programming, Mem. Fac. Sci. Kyushu Univ. Ser. A 30 (1976), 25-42.

[3] Iwamoto, S.: Inverse dynamic programming II, Mem. Fac. Sci. Kyushu Univ. Ser. A 31 (1977), 24-44.

[4] Iwamoтo, S.: Inverse theorem in dynamic programming II, J. Math. Anal. Appl. 58 (1977), 247-279.

[5] Iwamoto, S.: Inverse theorem in dynamic pragramming III, J. Math. Anal. Appl. 58 (1977), 439-448.

[6] Iwamoto, S.: An inverse theorem between main and inverse dynamic programming; infinite-stage case, in "Dynamic Programming and Its Applications" (M.L. Puterman, Ed.), pp. 314-334. Academic Press, New York, 1978.

[7. Iwamoto, S.: An inverse control process and an inverse allocation process, J. Operations Res. Soc. Japan 24 (1981), 1-18.

[8] Iw Amoto, S.: Inversion of dynamic programs and its applications to allocation processes, J. Math. Anal. Appl. 81 (1981), 474-496.

[9] Iwamoto, S.: A new inversion of continuous-time optimal control processes, J. Math. Anal. Appl. 82 (1981), 49-65.

Communicated by N. Furukawa

Received August 20, 1982 